Supporting information for

\title{
Ultrathin and highly tough hydrogel films for multifunctional strain sensors
}

Qian Zhang, Qian Wang, Guangyu Wang, Zilu Zhang, Shan Xia *, Guanghui Gao *

Polymeric and Soft Materials Laboratory, School of Chemical Engineering, Advanced Institute of Materials Science, Changchun University of Technology, Changchun, 130012, P. R. China

E-mail: xiashan@ccut.edu.cn; ghgao@ccut.edu.cn 
Table S1. The specific content of each material in the hydrogel film.

\begin{tabular}{lccc}
\hline Sample & PVA $(\mathrm{g})$ & $\mathrm{C} / \mathrm{P}(\mathrm{mL})$ & $\mathrm{H}_{2} \mathrm{O}(\mathrm{mL})$ \\
\hline HF(PVA3) & 0.6 & 0 & 20 \\
HF(PVA3-C/P1) & 0.6 & 6.7 & 13.3 \\
HF(PVA3-C/P2) & 0.6 & 6.7 & 13.3 \\
HF(PVA3-C/P3) & 0.6 & 6.7 & 13.3 \\
HF(PVA5) & 1.0 & 0 & 20 \\
HF(PVA5-C/P1) & 1.0 & 13.3 & 6.7 \\
HF(PVA5-C/P2) & 1.0 & 13.3 & 6.7 \\
HF(PVA5-C/P3) & 1.0 & 13.3 & 6.7 \\
HF(PVA7) & 1.4 & 0 & 20 \\
HF(PVA7-C/P1) & 1.4 & 20 & 0 \\
HF(PVA7-C/P2) & 1.4 & 20 & 0 \\
HF(PVA7-C/P3) & 1.4 & 20 & 0 \\
\hline
\end{tabular}




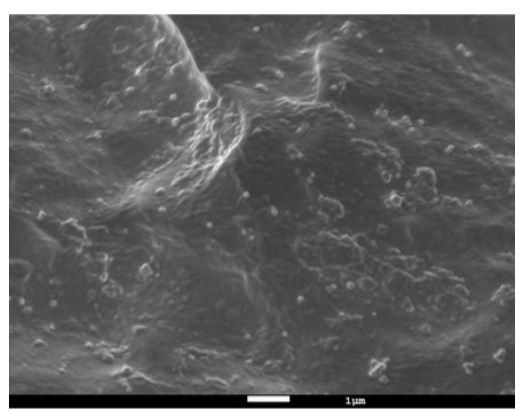

Fig. S1. SEM image of hydrogel film at high magnification 


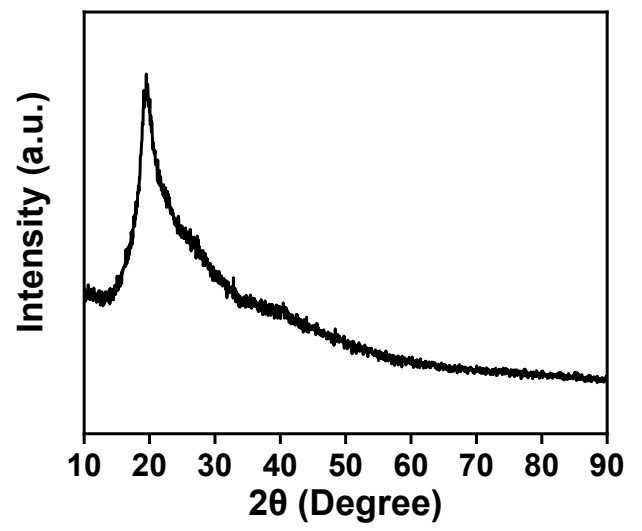

Fig. S2. XRD of the hydrogel film. 

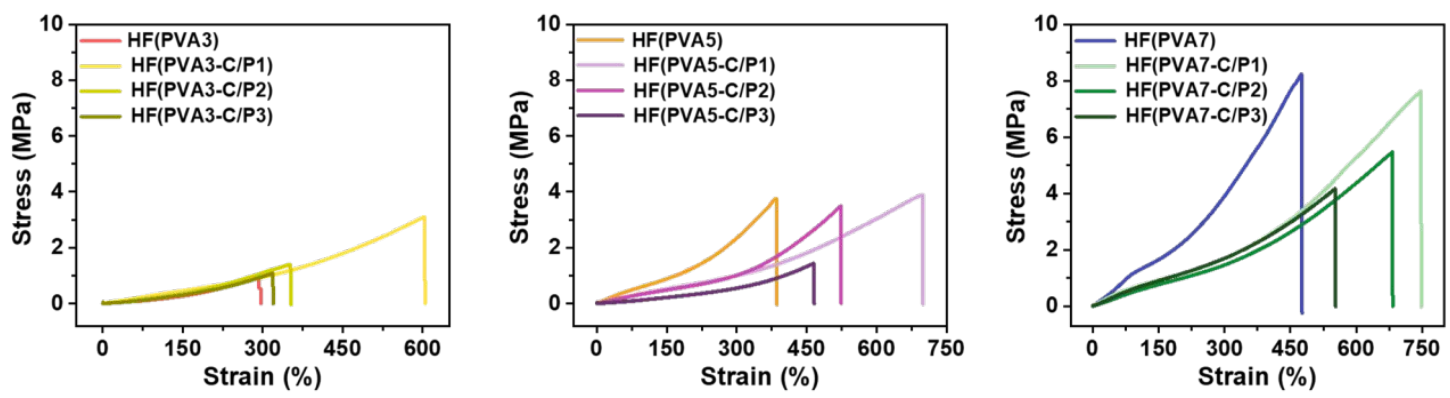

Fig. S3. Stress-strain curves of hydrogel films prepared with different contents of PVA and C/P. 